Unexpectedly, Dinerstein then takes us to the United States, to Michigan, to visit the Kirtland's warbler (pictured), another rare species with a small range. Its existence suggests that the special places that host rare species can be anywhere, but then begs the question of where rare species are found most often. There are salient laws about diversity, beyond those that Wallace described.

First, most species have small ranges. Only a few species have large geographical ranges, but they are by far the most familiar to us. I've watched common kingfishers (Alcedo atthis) on British streams and on lakes in Japanese cities. To see other species in the same genus, however, I had to travel to Madagascar and Bali, and would need to travel to different islands in the Philippines to see two more.

Second, species with small ranges tend to be concentrated in special places such as coastal Brazil or the eastern Himalayas. Most are tropical. Moreover, these areas are generally not where the greatest numbers of species are found in one place. So Dinerstein doesn't dwell on the Amazon: it has many species in any given location, but most have large ranges.

I sense that the Amazon disappointed Wallace too. It provided species, but not the unique ones his patrons craved. Darwin had no better luck in Patagonia, where the Beagle spent most of its famous voyage. When Wallace finally tripped over species with small, idiosyncratic ranges in the islands of Southeast Asia, and Darwin stopped briefly in the Galapagos on the way home, species rarity changed science forever.

Neither Darwin nor Wallace visited Hawaii, where Dinerstein's most poignant chapter is set. Different Hawaiian islands once had different "closely allied species". Dinerstein marvels at birds with strange names - the 'akiapola'au, for example - and even stranger beaks, and at lovely lobelias with flowers that fit other strange beaks. He sees a few of these in the wild; but most are extinct, just specimens in museums. Those that remain hang on in low numbers in the face of numerous threats such as habitat loss. When species such as these disappear forever, they take into oblivion all that we might learn about rarity and all that it tells us about the natural world.

Stuart Pimm is professor of conservation at the Nicholas School of the

Environment, Duke University, Durham, North Carolina, USA, and author of The World According to Pimm: a Scientist Audits the Earth.

e-mail:stuartpimm@me.com

\title{
STATISTICS
}

\section{Number-crunching in the raw}

\section{David Vaux welcomes a primer on how statistics mesh with life, from salesmen's spin to political polls.}

$\mathrm{E}$ ver wanted to encapsulate a quarterback's performance in a single number, wondered whether a bowling score was a descriptive statistic, or wished for a mathematical dissection of the Monty Hall box-choice problem? Then this is the book for you.

Like St Jude, Charles Wheelan has an interest in saving lost causes, and he has been invoking nudity to help in his quest. In an earlier book, Naked Economics (W. W. Norton, 2002), he attempted to bring some joy to the 'dismal science.' With Naked Statistics: Stripping the Dread from the Data, he faces another tough challenge: after all, statisticians have been described as people who are good with numbers but lack the personality to be accountants.

But this book is not intended for statisticians, because it doesn't go into the theory or mathematics in depth. Nor is there enough detail for clinicians, researchers or students. Instead, Naked Statistics targets the layperson, especially North American sports fanatics who want a deeper understanding of baseball, football, basketball, bowling, running and shooting statistics. But there is still plenty of thought-provoking material for the rest of us - even an amateur statistician like me - on stat-rich areas from politics, commerce and polling to the stock market.

There are, for instance, chapters explaining the spins used by salesmen, advertisers and politicians. One example is the blind taste test set up by a US beer company in the early 1980s, involving people loyal to another brand. Roughly half chose the tester's beer, but as Wheelan notes, the similar taste of midrange US beers could mean that the result was down to the law of probabilities. Wheelan is excellent on political polls, margins of error, and the importance of questioning a truly representative sample of the population, which is why surveys of sexual practices and internet polls can generate spurious results.

There is sound advice on what Wheelan reveals as different types of modern gambling. He explains how in the stock market you cannot expect to do better than the market index; that the only insurance you should buy is when you can't afford to easily cover the loss yourself; and that lottery tickets are for chumps. I would have liked more on the historical role of gambling, and how it was used by Fermat and Pascal to establish the mathematical basis of probability and statistics. It would also have been welcome to have practical tips other than "Don't do it", such as the theory and practicality of counting cards at casinos, and how to compare and judge risk.

Naked Statistics

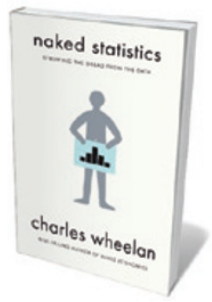

Naked Statistics: Stripping the Dread from the

Data

CHARLES WHEELAN W. W. Norton: 2013 302 pp. $\$ 26.95$ also covers descriptive statistics (which allows you to describe how a population is distributed), inferential statistics (which can be used to compare populations or answer hypotheses), and correlation and regression analysis (which can be used to see whether data, such as diet and health, are related). Wheelan explains their uses and key shortcomings, but without formulae and problems to solve. The appendices to some of the chapters do include more mathematical detail, and will give you a deeper understanding, especially if you study them in conjunction with the superb, free, statistical videos on the Khan Academy website (http://www.khanacademy.org).

For a deeper explanation of statistics and a glimpse at a future in which we are not subject to the tyranny of $p$ values - the most misunderstood statistical concept in research - I recommend Geoff Cumming's Understanding the New Statistics (Routledge, 2011).

And if you would like to know more about the areas Wheelan points to as hotbeds of use and abuse, take a look at Proofiness by Charles Seife (Viking, 2010) for the political angle, and Bad Pharma by Ben Goldacre (Fourth Estate, 2012), which looks at medical research and the pharmaceutical industry. These provide enough factual examples to get your blood boiling - without taking your clothes off.

David L. Vaux is deputy director of the Walter and Eliza Hall Institute of Medical Research, Melbourne, Australia.

e-mail:vaux@wehi.edu.au 